\title{
Rethinking 'Vulnerability' and Social Protection for Children Affected by AIDS
}

\author{
Jerker Edström
}

\begin{abstract}
1 Introduction
Social protection as a response to child and livelihood vulnerability has the potential to become a crucial element of comprehensive strategies to tackling the HIV epidemic. However, there remains a need to better conceptualise vulnerability itself. In this article, I critically reflect on some issues and gaps in targeting HIV-affected children and examine the thinking behind social protection for children in communities affected by HIV.
\end{abstract}

\section{Vulnerability and HIV and AIDS}

Robert Chambers reminded us that 'Vulnerability ... refers to exposure to contingencies and stress, and difficulty in coping' (Chambers 1989). That is, it has two senses - one anticipative of exposure and the other of consequences. In linking AIDS to

development, Barnett and Whiteside (2002) describe vulnerability as 'features ... that make it more or less likely that excess morbidity or mortality associated with disease will have negative impacts', and this has been followed by others (Gillespie 2006). They apply the idea of 'susceptibility' to describe what is otherwise referred to as vulnerability to exposure, or to infection.

However, susceptibility is commonly understood as the 'embodied' part of vulnerability to infection, as opposed to other predispositions, referred to as contextual or structural vulnerability (Bates et al. 2004). Several development writers also pick up on a similar internal/external distinction (e.g. Chambers 1989). Sinha and Lipton (1999) argue that vulnerability, with frequent exposure to hazards, coexists with and creates agency and resilience, including avoidance capacity, which goes beyond the passive sense of resilience and vulnerability to shocks.
In order to relate both HIV and AIDS to social protection and development, as well as to child development and welfare, we must include notions of susceptibility, resilience, vulnerability and responsiveness. Vulnerability - particularly related to health, child development, nutrition or reproduction - combines embodied and personal biological and psychological dimensions of susceptibility/resistance and sensitivity/responsiveness, with contextual interpersonal and environmental dimensions.

As life-extending anti-retroviral treatment is becoming more accessible, living with HIV is an increasingly long-term situation, rather than a transient shock. The resilience sometimes created by an HIV-positive or AIDS-affected status and identification can itself change the likelihood of various impacts, for better or worse.

\section{Why are HIV and AIDS important to understanding child vulnerability?}

Even with the gradual introduction of anti-retroviral treatment, the life-cycle of the virus, with its associated waves of infection, disease, deaths and orphaning, can result in each human generation being born into a context of decreasing life expectancy, rapidly increasing 'lifetime risks' of infection and increased acquired - and transmitted - drug resistance of the virus with serious implications for the health of future generations (Barnett 2005), thus contributing to a complex set of interlocking and dynamically evolving vulnerabilities.

In terms of context, absolute poverty is not the main issue driving the epidemic or its impacts, but issues of social fragmentation, ill health and lack of support often matter more. Households with chronically sick members have been found to be more food 
insecure, and a much larger percentage of orphans than non-orphans live in households that are food insecure with child hunger (Rivers et al. 2004). The internal biophysical impacts of hunger are intergenerational and the most important phase for malnutrition impacting on children's chances is from in utero to two years of age. The nutrition of young girls is also important to reducing future health risks linked to pregnancy and future susceptibility to HIV infection, particularly where girls have sex at a young age. So, the vulnerability to impacts of nutritional stress in early childhood often translates into vulnerability to infection after a decade or so.

Poverty is only one aspect in various complex dynamics between the different dimensions of human wellbeing. Economics, for example, impact on the social and vice versa. Orphans appear to be less likely to attend school than non-orphans (Landis 2003) and when there is economic hardship for vulnerable children and their carers, educational investments tend to suffer first - particularly for girls. This matters, since girls are particularly vulnerable to threats like early pregnancy or HIV infection - beyond internal susceptibility - relating to gendered discrimination, education, social norms and power. Neither purely economic nor purely sociocultural analyses are adequate to fully capture these inter-relationships.

While clearly necessary, there is a question of whether 'the household' is also sufficient as a unit of analysis to appreciate the dynamics of vulnerability to HIV and AIDS. In research on the impact of AIDS on livelihoods in Zambia (Drinkwater et al. 2006), the impact of HIV and AIDS deaths was found to 'cluster' within community networks, with traceable impacts over several years.

The 'household framework' is also rendered inadequate by the fact that there are increasing numbers of children who are at risk of separation from their families. Very little is known about street children in sub-Saharan Africa (including their HIV prevalence), although some research has been done on child labour and street children (Rau 2003). The reality of child sexuality as well as child labour is often overlooked and the 'domestic' situation of street children tends to keep them broadly outside sanctioned social norms, laws and services.

A key issue in the inter-generational reproduction of resilience/vulnerability is the passing down of assets as well as knowledge, 'roots/identity', social claims and 'legacy'. There are many important social, cultural, legal and political gender dimensions to the protection and vulnerability of children's economic assets and broader interests, which are not well researched. In the South African policy discourse, for example, women are reportedly not seen as agents in the process of preparing their children and future caregivers, or of planning for the future (Norman et al. 2005). Few sources specifically analyse the role of fathers in depth and much of the literature on inheritance examines rights in relation to widows rather than children.

There has been relatively little exploration of the longer-term macro-economic impacts of investments in child-focused development, or of the HIV-related impacts on children of longer-term economic policy. Some evidence suggests that World Bank and IMF adjustment policies may produce conditions which worsen women and children's vulnerability to HIV (de Vogli and Birbeck 2005).

\section{Social protection and targeting children}

The objective of social protection is broadly to reduce the economic and social vulnerability of poor, vulnerable and marginalised groups and to enhance the social status and rights of the marginalised, by providing income or consumption transfers. Debates on 'social welfare' and 'social assistance' have focused mainly on protective assistance to the poorest and most vulnerable, as well as sometimes preventive efforts through insurance and pooling of resources (usually to deal with impacts of shocks, rather than to actually prevent them). The idea of 'social protection' can also take on a broader perspective to include promotive and transformative actions (Devereux and Sabates-Wheeler 2004) and could lend itself to building a more balanced understanding of vulnerability, resilience and agency, which responds to the complex needs of real people. $A$ reconciled view of vulnerability - as also anticipative of exposure - provides for a broader set of ex ante options under all four types of social protection responses. Targeting should take account of vulnerability, in the above respects, to integrate protection strategically for the right people on the margins in the right ways.

So, how to identify the 'right' children? While most agree that the label of 'AIDS orphan' can be stigmatising, there is still no clear consensus on which 
children are most important to reach (labelled or not). Many argue that interventions should be directed to all vulnerable children and their communities, and integrated into other programmes to promote child welfare and reduce poverty, and therefore should not target on the basis of HIV or AIDS at all. Vulnerability is indeed more the issue, but the conclusion does not follow and it makes an AIDS-specific analysis and response more problematic. The argument also avoids the fact that many children do suffer from AIDSrelated discrimination, regardless of targeting. Major problems do create special needs and, while too narrow targeting can indeed precipitate harmful stigmatisation, too broad targeting tends to diffuse impact.

Careful attention to gender, age and family relationships is needed to help us identify important gaps in current approaches to targeting.

Orphanhood is not the main problem, although it clearly matters. In terms of orphans, those with one parent alive are often more vulnerable than those who have lost both parents, particularly when the latter are fostered in family settings. As noted, sickness in the household (e.g. of a parent) is often more of a threat to child education and welfare, than is orphaning per se.

Small children and older teens are often ignored in targeting responses, which misses important opportunities for addressing gendered intergenerational dynamics in the reproduction of poverty and HIV-related vulnerability, as well as gender constructs. Gender differentiation in children is a neglected area and 'children' are often seen as a gender-neutral category, with the same needs and vulnerabilities.

Evidence suggests that communities are better than governments or formal NGOs at targeting and reaching those most in need (Foster 2005). Community-level targeting is now being used for certain responses, and 'clusters' is an interesting avenue to explore further. Community targeting can indeed reduce stigma and enhance sustainability, but it can also introduce bias and leakage. Communities have sometimes been found to reinforce patterns of discrimination, as the lifestyles and livelihoods of the most vulnerable are often seen as a threat to social codes and norms. Nevertheless, to help most vulnerable children, a primary concern is to also support the household and carers. Support to older carers was neglected until fairly recently, but is now receiving more attention.

Targeting households will not be enough to effectively reach street children and those most vulnerable, such as those selling sex or injecting drugs. It is generally assumed that they will be 'picked up' by HIV programmes for sex workers and injecting drug users. This is a serious mistake, given the explosive combination of children and sex or drugs for most implementation agencies and the increasing hostility to pragmatic harm reduction approaches in major donor organisations.

\section{Current approaches for supporting children and some gaps}

Debates continue about whether broad-based and equitable poverty reduction should be favoured over a focus on specific disadvantages associated with marginalisation, and of the role of the state vs that of communities in addressing these problems. We clearly need a range of complementary approaches, and any realistic appreciation of vulnerability and social change must recognise the need for focused transformative agendas alongside reducing broader inequity. The distance between ideal approaches and reality, however, remains large.

Traditional fostering systems in Africa, supported by community programmes, will continue to care for most vulnerable children, provided that coping mechanisms are not undermined by our best intentions. State and NGO systems of support need to recognise the central role played by families and communities and some argue that they need to ensure that they strengthen extended family and community support mechanisms (Foster 2005). We must also recognise the limitations of these, however. For 'the most' vulnerable - as opposed to for 'most' - transformative empowerment often requires initially bypassing or challenging broader community mechanisms and realities. There is an urgent need to provide alternative models to family care to address the needs of, and empower, vulnerable children themselves.

Equitable access to services is essential for effective social protection and evidence from east and southern Africa suggests that achieving multiple impacts with a cash transfer involves linking their delivery with the delivery of basic services, such as immunisation, HIV and AIDS awareness, or nutrition 
education. Cash transfers are a key economic intervention, but as part of a broader range of social protection measures for child wellbeing. Others include access to and quality of health, education and other services for all children, child protection and psycho-social support. For the greatest number of children vulnerable to becoming affected by AIDS, the most important priority may be their parents' access to treatment for staying well for as long as possible and social protection must be better integrated with the needs of adults and children with HIV.

While food assistance alone will not address the complex needs of HIV-positive adults or affected children, food and nutrition support can have an important role to play within an integrated framework of social protection. For one thing, food and good nutrition are essential to effective HIV treatment. Food for education (FFE) has a positive impact on absolute school enrolment. In programmes that combined the provision of takehome rations for girls with on-site feeding for all pupils, girls' absolute enrolment rates were sustained year on year, and their dropout rates declined particularly in the higher grades, with crucial HIV vulnerability-reducing potential - both short and long term

There is no broad consensus on whether microcredit 'qualifies' as an income transfer normally associated with social protection, but many argue that innovation in microfinance to support HIV and AIDS-affected or other vulnerable households should be encouraged, accompanied by close scrutiny of the discrimination in communities that may result in exclusion of those affected by HIV and AIDS (Slater 2004). Few current programmes reach HIV-positive people and some simply combine HIV awareness activities with microfinance projects, without significantly deeper analysis. There is an increasing interest in developing this important field, however.

Of 36 African countries reviewed in a 2004 'OVC Programme Effort Index', only a few had revised or reviewed any laws for orphans and vulnerable children and even fewer had the resources to enforce existing laws (UNAIDS et al. 2004). In South Africa, for example, the rights of children vulnerable to growing up in child-headed households had not been sufficiently addressed by 2004 (Sloth-Nielsen 2004). The law prevents children under 16 and heading households from receiving the child support grant on behalf of younger siblings. There is no monitoring of discriminatory practices against children in child-headed households or those affected by HIV and AIDS. While little systematic monitoring is available, issues of land-grabbing and lost inheritance of children in several countries are commonly referred to in the literature.

When a gendered distinction is made in programmes, it is often limited to highlighting the vulnerability of girls to sexual violence, pregnancy or HIV infection. The needs of girls are usually 'lumped in' with those of adolescent girls and women, thereby ignoring the specific needs and issues of young girls - let alone young boys. Responses that do specifically target boys and girls, however, show better attitudes to gender equality as well as improved resilience (Barker and Girard 2003). Many are predicated on and reinforce hopelessly generalised gender norms, such as 'mothers are the carers', 'fathers are earners or absent' and 'children are sexless'. Few integrate deeper gender analysis in how they address vulnerability, before, during and after crises, or over generations.

\section{Conclusion}

A gendered and inter-generational understanding of vulnerability provides a better platform for relating ideas of resilience, resistance and responsiveness to more socially embedded notions of transfers and transformative social protection. An obvious challenge lies in balancing and interfacing equitable broad-based official programmes and policies with context-sensitive local responses, in a way which draws on the strengths of both. Another is integrating issue-specific programmes and services with transformative social protection, in a way that targets the most vulnerable and marginalised in the right ways, transforming their vulnerability into resilience to exposure (including avoidance capacity), as well as to impacts.

It is precisely those who fall between the familiar social constructs who tend to be the most vulnerable and also tend to slip though the holes in 'safety nets' or off the rough margins of 'trampolines'. Paradoxically, their non-conformity with its associated risk-taking expertise is often also their main source of resilience, at the same time as placing them at greater vulnerability. If we are to comprehend the architecture of this vulnerability and 
if their resilience is to be channelled in a positive transformative direction (rather than the reverse), we must learn to hear them better. Not only are they crucial to a more equitable society and a sustainable

\section{References}

Barker, G. and Girard, F. (2003) 'My Father Didn't Think This Way: Nigerian Boys Contemplate Gender Equality', Quality/Calidad/Qualite 14, New York: Population Council

Barnett, T. (2005) HIV/AIDS and Vulnerability: Sundering the Bonds of Human Society, Eldis Resource Guide 2005, Brighton: IDS

Barnett, T. and Whiteside, A. (2002), AIDS in the Twenty-First Century: Disease and Globalisation, Basingstoke: Palgrave Macmillan

Bates I., Fenton, C., Gruber, J., Lalloo, D., Lara, A.M., Squire, S.B., Theobald, S., Thomson, R. and Tolhurst R. (2004), 'Vulnerability to Malaria, Tuberculosis and HIV/AIDS Infection and Disease. Part 1: Determinants Operating at Individual and Household Level', The Lancet, Infectious Diseases 4: May

Chambers, R. (1989) 'Vulnerability, Coping and Policy', IDS Bulletin 20.2: Editorial Introduction

Devereux, S. and Sabates-Wheeler, R. (2004) Transformative Social Protection, IDS Working Paper 232, Brighton: IDS

de Vogli, R. and Birbeck, G.L. (2005) 'Potential Impact of Adjustment Policies on Vulnerability of Women and Children to HIV/AIDS in SubSaharan Africa', Journal of Health, Population and Nutrition 23.2: 105-20

Drinkwater M., McEwan, M. and Samuels, F. (2006) The Effects of HIV/AIDS on Agricultural Production Systems in the Zambia: A Restudy 1993-2005, Washington DC: Renewal, CARE, International HIV/AIDS Alliance, Food and Agriculture Organisation (FAO) and Swedish International Development Cooperation Agency (SIDA)

Foster, G. (2005) 'Under the Radar - Community Safety Nets for Children Affected by HIV/AIDS in Poor Households in Sub-Saharan Africa', in UNRISD (ed.), Community Responses to HIV and AIDS, Harare: United Nations Research Institute for Social Development (UNRISD) social contract, but they are also key to the future of the epidemic and societies' ability to respond to similar threats in the future.

Gillespie, S., ed. (2006) 'AIDS, Poverty and Hunger: An Overview', AIDS, Poverty, and Hunger: Challenges and Responses: HIV Lens Needed to see Interactions Between Food, Poverty and HIV, Washington DC: United States Agency for International Development (IFPRI)

Landis, R. (2003), Widening the 'Window of Hope': Using Food Aid to Improve Access to Education for Orphans and other Vulnerable Children in SubSaharan Africa, Rome: World Food Programme (WFP)

Norman, A., Kadiyala, S. and Chopra, M. (2005) Placing HIV-positive Mothers at the Centre of Planning for Orphans and Vulnerable Children: A Case Study of South Africa, Washington DC: Renewal

Rau, B. (2003) HIV/AIDS and Child Labour: A State-ofthe-art Review with Recommendations for Action, Geneva: International Labour Organisation (ILO)

Rivers, J., Eva, S. and Mason, J. (2004) Nutritional and Food Security Status of Orphans and Vulnerable Children, Washington DC: United States Agency for International Development (IFPRI)

Sinha, S. and Lipton, M. (1999), 'Damaging Fluctuations, Risk and Poverty: A Review', background paper for the World Development Report 2000/2001, Brighton: Poverty Research Unit, University of Sussex

Slater, R. (2004) The Implications of HIV/AIDS for Social Protection, London: United States Agency for International Development (DFID)

Sloth-Nielsen, J. (2004) Realising the Rights of Children Growing up in Child-headed Households: A Guide to Laws, Policies and Social Advocacy, Cape Town: Community Law Centre, University of the Western Cape

UNAIDS, USAID and Futures (2004) National Response to Orphans and Other Vulnerable Children in sub-Saharan Africa: The OVC Programme Effort Index, Joint United Nations Programme on HIV/AIDS (UNAIDS), United States Agency for International Development (USAID) and Futures 